\title{
RETRATOS SOCIOLÓGICOS DO MARACATU DE BAQUE SOLTO: Percursos, disposições, práticas e variações culturais
}

\section{SOCIOLOGICAL PORTRAITS OF MARACATU DE BAQUE SOLTO: Paths, dispositions, practices and cultural variations}

\author{
José Roberto Feitosa de Sena*
}

Ninguém segue uma única vida, todos se multiplicam em diversos e transmutáveis homens Mia Couto, escritor moçambicano

(Cada homem é uma raça)

\begin{abstract}
Resumo
O presente texto, resultado de uma pesquisa doutoral, pretende colaborar para reflexão sociológica sobre a necessidade de abordagens em escala individual aplicadas aos estudos de cultura popular investigando os atores do Maracatu de Baque Solto, manifestação oriunda das classes populares em Pernambuco. Tentando pensar a cultura popular sob a perspectiva disposicionalista e contextualista, a pesquisa traz à baila o caso dos indivíduos visando observá-los/analisá-los em diferentes contextos da ação, refazendo suas trajetórias sociais a fim de analisar, em nível diacrônico-sincrônico, suas ações plurais e variações culturais. Tal objetivo foi possível com a aplicação dos retratos sociológicos de indivíduos, a partir da reconstrução de suas trajetórias de vida nos mais variados e contínuos processos plurais de socialização. Essa abordagem se embasa, principalmente, na perspectiva teórico-metodológica de Bernard Lahire e nos casos de aplicação/atualização desta na sociologia lusófona, especialmente portuguesa. A investigação aprofundada em escala individual não negligencia os demais níveis e é pertinente para a percepção das micromobilidades, hibridismos, circularidades culturais e variações inter e intraindividuais. O artigo apresenta uma discussão teórico-metodológica sistemática e, ao final, um dos retratos sociológicos resultantes da pesquisa.

Palavras-Chave: Retratos sociológicos. Sociologia disposicionalista. Ator plural. Cultura popular.
\end{abstract}

\begin{abstract}
The present text, the result of a doctoral research, intends to collaborate for sociological reflection on the need of individual - scale approaches applied to studies of popular culture investigating the actors of Maracatu de Baque Solto, a manifestation coming from the popular classes in Pernambuco. Trying to think of popular culture from a dispositional and contextualist perspective, research brings to the surface the case of individuals aiming at observing / analyzing them in different contexts of action, rethinking their social trajectories in order to analyze, at the diachronic-synchronic level, their plural actions and cultural variations. This objective was possible with the application of the sociological portraits of individuals, from the reconstruction of their life trajectories in the most varied and continuous pluralistic processes of socialization. This approach is based mainly on the theoretical-methodological perspective of Bernard Lahire and in the cases of application / update of this in Portuguese sociology. In-depth research on an individual scale does not neglect the other levels and is pertinent for the perception of micro-mobility, hybridity, cultural circularities and inter- and intra-individual variations. The article presents a systematic theoretical-methodological discussion and, at the end, one of the sociological portraits resulting from the research.
\end{abstract}

Keywords: Sociological portraits. Sociological dispositional. Plural actor. Popular culture.

\footnotetext{
* Graduado em História (Unicap), mestre em Ciências das Religiões (UFPB) e doutor em Sociologia (UFPB) com doutorado-sanduíche na Universidade do Porto (UPorto-Portugal). Professor de Graduação da Faculdade Elo Faelo (Recife-PE), da Faculdade de Ciências Humanas e Sociais de Igarassu - (Facig) e professor de Pós-Graduação Lato Sensu (Especialização) em Ciências da Religião e Ciência Política das Faculdades Integradas de Vitória de Santo Antão - Faintvisa. Atua ainda como professor de sociologia e filosofia no Ensino Médio.
} 


\section{Indivíduo e cultura popular na perspectiva da sociologia disposicionalista franco-portuguesa}

O maracatu rural, também conhecido como Maracatu de Baque Solto, é uma manifestação cultural, de origem afro-brasileira e indígena, oriunda das classes populares da região interiorana da Zona da Mata Norte de Pernambuco e muito presente também nos bairros periféricos da Região Metropolitana do Recife. As apresentações do maracatu, resultantes de intensos trabalhos e relações de bastidores, fazem parte do cotidiano e dos calendários de atividades anuais dessas agremiações. No entanto, é o carnaval o momento mais esperado e é se preparando para este que muitos integrantes voltam maior parte de seus afazeres culturais no interior da agremiação popular (SENA, 2012).

Os estudos sobre o Maracatu de Baque Solto se limitam a tentar compreender suas histórias e/ou o contexto sociocultural dos grupos. Muitos estudos até o presente, desde os trabalhos de cunho folclorista aos de caráter acadêmico, enfocaram nos estudos estruturais e grupais, e as poucas pesquisas em escala biográfica não se aprofundaram nas variações dos indivíduos, mas sim, reafirmando seu protagonismo típico-ideal dentro de um campo delimitado. Algumas dessas abordagens, por mim elencadas e analisadas no estado da arte de minha dissertação (SENA, 2012) fornecem um relevante contributo para a compreensão dos maracatus, mas deixam lacunas que merecem ser inquiridas.

Em geral, não tive conhecimento de estudos em escala individual no sentido de visualizar os deslocamentos e variações entre indivíduos dentro do próprio espaço social de atuação cultural, ainda mais quando se pretende analisar os deslocamentos e variações intraindividuais. Desse modo, uma mudança de escala sem negligências e um aprofundamento investigativo centrado no indivíduo, considerando seu passado e seu contexto presente, pode nos revelar atores plurais dentro e fora do maracatu, bem como pluralidades dentro e fora do espaço sociocultural de pertença.

Visando a um direcionamento para essa perspectiva investigativa e analítica, situo a presente pesquisa na linha teórico-metodológica disposicionalista em escala individual, proposta pelo sociólogo francês Bernard Lahire, que apresenta novas exigências metodológicas, pois, para compreender a pluralidade interna dos atores é necessário dotarmo-nos de dispositivos que permitam observar diretamente ou reconstruir indiretamente, por meio de diversas fontes, a variação dos comportamentos individuais segundo os contextos sociais (LAHIRE, 2001, p. 262).

Procura enfocar na análise em escala individual sem negligenciar as coletividades do social, visa mergulhar na trajetória do indivíduo para assim ter considerações consistentes acerca da sociedade. Adentrando no processo de socialização do ator, torna-se possível reconhecer as disposições que atuam nas suas ações presentes, suas variações externas, e, especialmente, internas, permitindo refazer um perfil sociocultural do ator. Quando se pretende destacar as variações internas de um indivíduo, percebe-se a amplitude das variações entre indivíduos. Cada ator é singular e plural, pois é produto inacabado de uma gama infindável de experiências 
socializadoras. Essas variações apresentam, de certa maneira, o funcionamento do mundo social, uma vez que os processos de socialização cultural dos indivíduos nunca se perfazem em "quadros únicos e homogêneos" (LAHIRE, 2006).

A proposta teórico-metodológica de Bernard Lahire aplicada a tal objeto deve nos ajudar a "prolongar" os estudos sobre cultura popular, tendo como mote estudos de caso de atores do maracatu e nos permitir reconhecer muitos desses homens e mulheres que dele fazem parte, construindo seus retratos, considerando os domínios com e sem roupa de maracatuzeiro. Dito de outra forma: visando analisá-los dentro do maracatu e para além do maracatu.

Apesar da inserção em construção da sociologia de Bernard Lahire no Brasil (cuja recepção me parece ainda é maior entre os cientistas da educação que entre sociólogos), as abordagens que se realizam são em geral ainda incipientes e contam com aplicações do método sem muitas discussões e/ou adaptações metodológicas. No que se refere à aplicação do método, mesmo quando certas especificidades são consideradas e justificadas, não nos permite considerar atualizações extensivas da metodologia. À medida que a sociologia de Bernard Lahire vai ganhando espaço acadêmico no Brasil, é possível que novos trabalhos que se utilizam predominantemente da metodologia dos retratos possam elucidar discussões e adaptações que permitam avançar e atualizar tal dispositivo, de acordo com as especificidades brasileiras.

Numa posição, que me parece alguns poucos passos à frente do Brasil, a sociologia empírica de Bernard Lahire vem ganhando muito espaço institucional na sociologia de Portugal ${ }^{1}$, especialmente entre estudos dedicados à educação e à cultura, aplicando de modo adaptativo e seletivo seus dispositivos metodológicos ao contexto lusitano (AMÂNDIO; ABRANTES; LOPES, 2016). Considerado um dos maiores nomes da sociologia da educação e da cultura em Portugal, João Teixeira Lopes ${ }^{2}$ é um revisor/atualizador do suporte teórico-metodológico da sociologia disposicionalista em escala individual, aplicando o método dos retratos sociológicos a contextos socioculturais específicos.

O retrato sociológico consiste em entrevistas biográficas de caráter semidiretivo com o objetivo principal de perceber a forma como as disposições individuais se formam e incorporamse nos diferentes papéis sociais do ator, nos múltiplos mundos sociais que perpassam sucessiva, alternada, paralela e simultaneamente ao longo da vida. Nas pesquisas coordenadas pelo autor em que se utiliza deste dispositivo, procura fazê-lo de forma aplicada, isto é, subordinado a um problema de pesquisa direcionado, embora sem nunca deixar de retirar ilações substantivas para possíveis reconstruções da teoria social (AMÂNDIO; ABRANTES; LOPES, 2012)

\footnotetext{
1 Em Lopes, Amândio e Abrantes (2012), no prefácio da obra dedicada à recepção e à aplicação da sociologia lahireana em Portugal, o próprio Lahire escreve que foi no pais ibérico que seus trabalhos tiveram maior recepção e aplicação entre as pesquisas sociológicas.

2 Professor catedrático da Universidade do Porto - Uporto (Portugal) e presidente da Associação Portuguesa de Sociologia - APS. Durante realização do meu estágio doutoral como bolsista do Programa Doutorado Sanduíche no Exterior - PDSE/Capes em 2017 tive sua orientação no Instituto de Sociologia da Uporto, o que resultou em parte das indicações teórico-metodológicas presentes neste artigo.
} 
Amândio, Abrantes e Lopes $(2012,2016)$ atualizam a metodologia de Lahire e propõe novos métodos e técnicas a partir da especificidade da pesquisa empírica por ele aplicada. $O$ retrato configura assim um lócus metodológico capaz de inquirir, periciar e perscrutar o objeto de análise, configurando ainda um dispositivo de articulação entre a análise sociológica (interpretação em segundo grau) das pluralidades disposicionais e contextuais das práticas e uma narrativa em voz própria, a polifonia do nativo (interpretações em primeiro grau).

Visando dar um zoom da escala macro e estrutural, que analisa os grupos e seus campos, à escala micro e individual, que analisa a trajetória e as variações do ator, apresento um dos retratos sociológicos elencados na minha tese de doutoramento. É o retrato de Bernardo Soares ${ }^{3}$, neste quadro descritivo-analítico apurado e plural, sincrônico e diacrônico, podemos perceber a trajetória múltipla e tensa do indivíduo, pontuando não só suas variações e heterogeneidades culturais, mas também certos antagonismos.

\section{RETRATO SOCIOLÓGICO DE BERNARDO SOARES}

Vicissitudes e variabilidades de uma trajetória plural conciliadora dos inconciliáveis

Trago em mim o inconciliável e é este o meu motor Papetala, escritor angolano. (Mayombe)

Bernardo Soares, 28 anos, é um jovem que iniciou muito cedo sua participação no maracatu, superando os medos de infância. Mora com a mãe, irmã e avó. Teve o pai precocemente ausente. Recebe influências diversas, especialmente do irmão e de amigos. Demonstra grande competência e apetência pela cultura popular. É sujeito de consumos ecléticos e mistura gêneros em suas práticas culturais. Além de mestre de maracatu, demonstra acentuado gosto/consumo por futebol, UFC, música brega, participa de disputas de break dance, é marcador de quadrilha e se diz apaixonado por Cavalo Marinho. É engajado nas práticas culturais comunitárias, compondo associações culturais. É um sujeito empolgado e atuante na cultura local. Teve uma experiência significativa na relação com artistas locais reconhecidos nacional e internacionalmente. Viajou por vários estados do Brasil e países europeus. Releva as experiências que o trabalho lhe trouxe, mas se queixa das conflitantes relações entre o operariado industrial, contudo, foi também na indústria que ele exerceu sociabilidade cultural relevante para sua atividade como mestre de maracatu. Iniciou sua frequência nos terreiros de umbanda de sua cidade como tocador (ogã). Passou a ter forte crença na umbanda e acentuar suas práticas ao adentrar no maracatu. Ultimamente estava se afastando por influência ambígua do irmão, que se tornou evangélico. Diz amar o maracatu, mas vê como muito provável deixar a cultura para "servir a Deus" ou tentar combiná-los.

Meu contato com o jovem retratado se deu por intermédio de outro retratado, Ricardo Reis, que conheci por meio do facebook e que se tornou meu interlocutor, apresentando muitos conhecidos seus da área, um deles foi Bernardo Soares. Eu já o conhecia por meio da mesma rede social, momento em que levantava muitos perfis de maracatuzeiros, realizando pesquisas neste

3 Bernardo Soares é um dos heterônimos de Fernando Pessoa, utilizado aqui como mero empréstimo figurativo. 
ciberespaço, momento em que iniciei minhas primeiras observações e impressões a cerca desse ator. Em contato com Ricardo Reis, combinamos de nos encontrar em um ensaio de maracatu. Foi nessa ocasião que o conheci pessoalmente, apresentado pelo supracitado interlocutor. No momento do primeiro contato presencial, já observei o quanto comunicativo, acolhedor e empolgado era aquele jovem mestre de maracatu. Recebeu-me com um abraço, chamando-me a todo tempo pelo nome, apresentando a amigos e me convidando para eventos diversos. Fiquei sempre a observálo até que, horas depois, antes do anoitecer daquele domingo, veio se despedir e lhe perguntei o porquê de ir tão cedo e ele com sorriso no rosto respondeu: "Vou ver meu timão jogar". Continuei a perguntar: "Qual é seu time?" E me responde com um sorriso ainda mais largo: "Corinthians", time paulista de futebol. A receptividade empática que recebi daquele jovem - aliada à forma aberta com que ele interagia, entrando em temas além do maracatu, mesmo que de modo muito incipiente naquele momento - despertou-me interesse em continuar a investigá-lo.

Dias depois, passamos a ter contato via redes sociais e em pouco tempo marcamos novos encontros que tinham o objetivo de observá-lo em suas práticas culturais. Estivemos em alguns ensaios e sambadas de maracatu e observei o quanto, de modo interativo e atuante, ele se movimentava nos contextos festivos, explorando a sociabilidade e expressando os elementos práticos característicos do quadro interacional da região sociocultural. Nessas atividades, estreitamos nossa aproximação e combinamos algumas entrevistas. A primeira delas se deu semanas antes do carnaval. Nas primeiras semanas de 2016 nos reunimos numa manhã de sábado, em um banco da praça principal da cidade, em frente à Igreja Matriz do município, tendo como pauta sua trajetória e práticas culturais, bem como os preparativos para o carnaval que se aproximava.

Depois da primeira, realizei a segunda entrevista semanas depois do carnaval, dias que antecediam as comemorações de Páscoa. Bernardo Soares, mais uma vez empolgado, comentava sobre o último carnaval.

$\mathrm{Na}$ terceira entrevista, que transcorreu no mês de julho, atravessando o conteúdo de sua trajetória, de maneira revisitada e aprofundada, abordei o tema das quadrilhas juninas, modalidade cultural característica dos festejos de São João em que ele exerce uma posição também de destaque como marcador ${ }^{4}$. Ao todo, foram 4 horas e 55 minutos de entrevistas registradas em gravador de áudio.

\section{Entre competências/apetências na cultura popular e de massa e o desejo iminente de conversão ao pentecostalismo: os múltiplos e multiplicáveis atores em um}

Bernardo Soares tem 28 anos. Nasceu no município de Paudalho, mas desde a primeira infância mora em Tracunhaém. Em sua casa, vive ele, sua mãe, sua irmã, seu tio e sua avó materna.

4 Figura-líder que coordena as coreografias e evoluções por meio de cânticos e expressão de ordem e interage com o público que, em torcida, assiste as apresentações competitivas de quadrilhas juninas. 
Sua irmã, ainda na menoridade, não trabalha; já ele, seu tio e sua mãe estão desempregados. A renda familiar é oriunda da pensão que a avó materna recebe do avô já falecido. Ao todo, os rendimentos não passam de dois salários mínimos. Para não ficar "sem fazer nada", ajuda em diversos serviços domésticos, como limpar a casa, lavar pratos, coletar o lixo e outros tipos de “arrumação". Tem um irmão a quem é muito próximo, mas não mora mais em casa. É casado, evangélico da igreja Assembleia de Deus e mora com a esposa e dois filhos.

Seu pai abandonou ele e seus irmãos ainda cedo. Conta que lembra pouco de sua convivência com o pai na mesma casa. Do pouco que lembra e que é realçado pelas histórias de sua mãe em tom de lamentação, relata o alcoolismo do pai e as frequentes agressões à sua mãe. Hoje, o pai, novamente casado e com dois outros filhos, mora em um município do sertão de Pernambuco e vai raras vezes, em visita, a Tracunhaém, quando nessas ocasiões depende de ajuda financeira dos filhos para o translado, porém, queixa-se Bernardo Soares, "não liga muito pra gente". A relação dele com a família paterna é tensa por conta da ausência afetiva do pai e pela não simpatia do filho por sua atual esposa, que o teria acusado injustamente por furto de um chapéu na casa da avó. Desde então, não fala com a esposa do pai e não frequenta com assiduidade a casa da avó paterna.

Bernardo Soares é um jovem com fortes e múltiplas disposições de atuação, com competências e apetências variadas, na cultura popular de sua região, transitando entre as linguagens locais e globais, adquirindo experiências plurais e movendo-se com facilidade pelo quadro interacional do contexto em que vive, trazendo a este, experiências adquiridas em outros mundos socializantes.

Entre os grupos culturais de que mais participa, está o Cavalo Marinho, em que se apresenta especialmente durante as festas natalinas, as quadrilhas juninas e, por fim, o Maracatu de Baque Solto, nas festas carnavalescas. Sobre o primeiro, ele tem mais apetência ${ }^{5}$ que competência ${ }^{6}$, uma vez que se dedica menos ao cavalo marinho que ao maracatu, mas relata que tal modalidade cultural é sua preferida. Quanto ao segundo, possui mais competência que apetência, pois, apesar de gostar muito de quadrilha junina, suas "paixões" são o cavalo marinho e o maracatu. No terceiro, mesmo afirmando gostar mais de cavalo marinho, possui forte apetência + competência. É no espaço social do maracatu que ele se realiza e exerce suas funções de maior destaque no quadro interacional mais amplo da região.

Oficialmente, no campo em que atua com mais aderência, Bernardo Soares é contramestre de Maracatu, figura que tem como função cantar os versos proferidos pelo mestre em repetição melódica. Na prática, ele é mais: além de exercer um papel de perfil organizativo, ele é mestre em muitas festas de maracatu e mesmo em apresentações oficiais quando o mestre de seu maracatu dá-lhe a oportunidade de cantar para o grande público.

\footnotetext{
5 Vontade, paixão, impulso voluntário, prazer em fazer.

6 Saber fazer, dominar meios e métodos do fazer, ter habilidade e destreza, conhecimento específico.
} 
Mas não só de momentos alegres e festivos se dá a vida desse jovem e talentoso agente da cultura popular. Bernardo Soares se queixa da falta de emprego e renda, está há dois anos desempregado e sem perspectivas concretas de conseguir uma vaga em algum posto de trabalho. Busca um novo emprego como uma prioridade em sua vida, pretende ajudar em casa, especialmente a sua mãe que também "tá parada", sonha ainda em fazer um curso superior de licenciatura em educação física, tem muita vontade de conseguir uma vaga de emprego e de formação superior na área da docência. Mas a cada encontro nosso, ele demonstrava frustração diante do passar dos dias e da não conquista do que deseja. Frente à situação de relação entrevistador-entrevistado e para além desta relação, me vi inserido, não muito diferente do que aconteceu em outras situações com outros entrevistados, num contexto de escuta, numa posição de ente amigável a quem se pode recorrer para o desabafo. Inevitavelmente retribuí com expectativa positiva e uma mensagem motivacional. A queixa do desemprego era constante no retratado, mas isso nem um pouco abalava seu entusiasmo e bom humor.

Bernardo Soares tem vivido de rendas provenientes de "bicos", como as atividades ${ }^{8}$ de pintura de peças artesanais feitas de barro na olaria de um amigo artesão e os baixos cachês que recebe em apresentações de maracatu. Essas apresentações acontecem mais nos dias de carnaval. Ele dá o exemplo do último carnaval em que ao todo recebeu R\$ 800,00, dos quais, metade do valor deu a sua mãe. Quando não são apresentações de carnaval, são esporádicas, pois não existe uma frequência regular; variáveis, pois os valores oscilam e quase sempre lhe são repassadas verbas pequenas, e, incertas, pois muitos dos acordos são feitos "de boca" e os grupos têm dificuldade de conseguir bons pagamentos. Consequentemente, encontram eventuais dificuldades, de repassar valores acordados, além dos longos prazos para quitação. Outra forma de lhe render um incerto "trocado" é por meio de apostas em resultados de jogos esportivos do Campeonato Brasileiro de Futebol. Para essa situação, conta, além do seu conhecimento em ternos de futebol, com uma boa dose de sorte.

Faz um bocado de tempo que eu to parado, mas graças a Deus que o povo me chama pra tocar, tem também dinheiro de aposta no Brasileirão que eu ganho, essa semana mesmo eu joguei 2 reais e ganhei 22 reais

Antes desses trabalhos informais, Bernardo Soares atuou como "cabo eleitoral" de um político local nos dois meses que antecederam as eleições municipais, função que lhe rendeu algum dinheiro e muitos contatos pelas interações em campanha, além de consolidar contatos com lideranças políticas de sua cidade. Com a vitória eleitoral desse candidato, uma vez empossado, ele lhe convidou para trabalhar como locutor numa rádio municipal. Nessa função,

7 Expressão que designa serviços esporádicos e de pouco valor remunerativo.

8 Mais informações sobre a precariedade do trabalho no Brasil ver: CARDOSO, Adalberto. A construção da sociedade do trabalho no Brasil: uma investigação sobre a persistência secular das desigualdades. Rio de Janeiro: Editora FGV/Faperj, 2010, 463 p. 
exercitou sua voz, destacado instrumento que dedica à cultura, especialmente ao maracatu, e exercitou as relações de comunicação por meio de um aparelho de longo e massivo alcance. Foi uma experiência relevante, pois esteve durante o carnaval numa posição diferente daquela mais habitual. Foi por um carnaval locutor de um polo na zona rural e ficou durante os três dias de carnaval a apresentar e comentar as agremiações que por lá passavam, estando diariamente em contato com inúmeros amigos do quadro local de interações. Relata que a experiência foi muito rica e, além de lhe garantir uma renda, abriu portas para conhecer mais pessoas e consolidar os contatos e conhecimentos que tecia. Mas não durou mais de 2 anos, e o prefeito da cidade lhe deu como proposta, para empregar sua mãe, que ele abrisse mão da vaga para outra pessoa. Inserido num evidente jogo político e preocupado em garantir empregabilidade para sua mãe, ele entrega o cargo de liderança na rádio e fica desempregado por um curto espaço de tempo até conseguir uma vaga de auxiliar de produção fabril.

No chão de fábrica, passou 1 ano e 3 meses como auxiliar de produção na indústria de calçados, único emprego de carteira assinada que já teve. Exerce as funções de pintor, operador no setor de reciclagem e operador de instrumentos na área de acabamento. Procurava adequar o horário de trabalho de modo que não o impedisse de participar das festas de maracatu. Conta que nos horários de intervalo para almoço ele interagia com um colega, também de maracatu, fazendo disputas de versos. Nessa época ele ainda não era mestre de maracatu, mas tinha muita admiração pela função. Combinava com o colega oponente para que apressassem a refeição e aproveitassem o tempo restante de intervalo, antes de retornar aos afazeres laborais, para cantar maracatu. Então, reuniam um público de amigos, que se dividiam em torcidas adversárias a agitar a tensa e descontraída disputa, de que ele muito se orgulha em recordar.

Bernardo Soares lamenta a saída da indústria, diz-se muito triste quando ouviu do seu superior: "Não precisamos mais dos seus serviços". Comenta que, se hoje fosse chamado para retornar, aceitaria, pois a situação de desemprego é muito difícil. Ele não tem participação em associação comunitária, mas, nas associações culturais de que faz parte exerce importantes trabalhos comunitários e de maneira voluntária. Sendo um conhecedor de práticas culturais variadas e características da região, atua como instrutor de oficinas para crianças e adolescentes. Diz-se muito satisfeito com o trabalho e que o "dinheiro não é o mais importante". Geralmente, realiza tais ações em escolas públicas, em associações e sedes de maracatu. A renda escassa limita sua satisfação pelo consumo, tendo dificuldades em adquirir produtos de interesse. Em casa, tem acesso à internet wifi, geralmente navega pela internet pelo celular ou, ocasionalmente, pelo notebook do irmão.

A vida escolar foi de intensas socializações, concluiu o ensino médio, mas há muito tempo que já não estuda, informa que na escola "era aquele cara que estudava, mas era largado também". Tinha uma postura ambivalente de aluno aplicado, interessado e participativo, mas gostava de se relacionar entre os mais indisciplinados, pois lá encontrava reação à monotonia do ensino tradicional. Nas sociabilidades interindivíduos no meio intraescolar ele teceu relações 
e experiências importantes de modo dialético com as experiências gerais que a escola lhe permitia. Relata que os professores passavam trabalhos e sempre se destacava nas apresentações de seminários, especialmente em temas relacionados à cultura.

Tem boas recordações desse tempo, fala de uma feira do conhecimento em que o tema foi o Movimento Manguebeat e que coube a ele se apresentar como Chico Science. Nesse dia, foi uma grande festa na escola, tomou o microfone e cantou músicas que mesclavam rock e maracatu. Ao final da apresentação, "foi resenha demais", cantaram músicas bregas antigas, num momento mais recreativo, chamando a atenção de todos os presentes. Conta que a sua equipe não teve uma das melhores notas da supracitada atividade escolar, mas o aprendizado "foi bom demais".

Em atividade similar, em comemoração aos festejos da semana do folclore, ele e amigos constroem um maracatu improvisado que eles denominam de Maracatu Patativa Dourada, uma alusão a um pássaro típico do continente sul-americano muito apreciado na região Nordeste do Brasil por sua variedade de cânticos. Recorda-se ainda de bons professores que teve e inclusive atribui a um deles o gosto por educação física que, além de ter relação com a dança, aborda diversas modalidades esportivas. Seu professor o influenciou a gostar da disciplina e ele, que já gostava de futebol, pôde perceber que a educação física estava muito além do futebol, aprendeu com o docente as variadas formas de esporte e que, mesmo no futsal, modalidade muito praticada por ele, existem coisas importantes a se abordar como estratégias de jogo, fundamentos, história, alongamentos e exercícios direcionados etc. Observei que através da relação com esse professor ele endossou disposições para a prática esportiva as tornando ativas para o interesse pela docência escolar.

Ainda não teve oportunidade de realizar o curso, mas as constantes barreiras não o impedem de manter tal sonho. Sua maior vontade é conseguir conciliar faculdade e trabalho. Para isso, precisa conquistar ambas as vagas. No momento, encontra-se entre os jovens enquadrados como geração "nem-nem" (nem trabalha, nem estuda) 9 . Contudo, observando de perto suas práticas de ação no quadro de interação local, constatamos que ele não se enquadra num perfil de aspectos de jovens estereotipados como ociosos. Pelo contrário, é na relação e atuação com seu contexto e com a aquisição/participação de atividades em contextos diversos, que ele encontra relevante aprendizado e exerce consideráveis funções para sua sociedade.

$\mathrm{Na}$ primeira infância, não gostava de maracatu. Com ajuda de sua mãe, recorda que se escondia ao ver um caboclo de lança passar pela rua em dias de carnaval. Essa relação com o maracatu nesse momento não é unilateral. Ela gesta um misto de "medo" e curiosidade. "Oxi catita? Caboclo de maracatu? Tinha medo! medo! Ficava os três dias de carnaval trancado em casa com medo, ai depois fui perdendo o medo".

9 Maiores informações sobre, ver: MOTEIRO, Joana. Quem são os jovens nem-nem?: Uma análise sobre os jovens que não estudam e não participam do mercado de trabalho. Rio de Janeiro: Fundação Getúlio Vargas, 2013. 
O medo é construído a partir das narrativas culturais que se propagavam pela região e é ponto de partida, aguçando a curiosidade, para buscar mais informações sobre o maracatu e, gradativamente, converter o medo por apetência. Tanto que a repulsa não durou muito. Ainda em casa teve muito contato com o avô que era mestre de mamulengo, prática que ele não seguiu, mas tomou gosto pela animação cultural popular. Com nove anos de idade, participou pela primeira vez do caboclinho, desfilava em cortejo vestido de índio. Tal experiência despertou-lhe interesse em "brincar" de arreamá ${ }^{10}$ de maracatu, pelas características fortemente indígenas dessa figura. Foi então, ainda adolescente, participar do primeiro grupo de maracatu. Lá, teve contato com um antigo mestre-caboclo da agremiação a quem ele chama de "meu avô de maracatu". Atribui a ele muitos aprendizados sobre maracatu, sentava-se ao lado do ancião e conversava por horas no terreiro frente à sede do maracatu. Logo o seu mestre passa a observar o interesse e destreza do adolescente, a quem apelida de "enxerido". Constata-se que, nessa relação, Bernardo Soares ativa disposições para a prática do maracatu, alargando-as para além da figura do arreamá e passa a desenvolver apetências + competência que o levaram a outras práticas intra e extramaracatu.

Já passou por cinco grupos de maracatus. No primeiro, aprendeu muito, sendo um abreportas para outros maracatus e diversas experiências. Com a saída do primeiro, segue para o outro onde vai tocar vários instrumentos percussivos no terno (conjunto musical composto por instrumentos de sopro e de percussão) da agremiação, função que lhe aproxima da musicalidade e das figuras do mestre e contramestre. Na mesma condição, participou de um grande Maracatu em Nazaré da Mata e, depois, visando galgar outros patamares no Maracatu, decide tentar a carreira de contramestre. Foi convidado para participar de um Maracatu de destaque, mas finalizou o contrato de participação devido a disputas de reconhecimento com outro mestre da mesma agremiação e, por isso, segue para o maracatu em que se encontrava no momento da pesquisa, a convite do presidente do grupo. Nessa agremiação, ele se manteve ao longo de toda a presente investigação, na condição de contramestre e aspirante de mestre, tomando não raras vezes tão função, de modo que é possível (e assim muitos amigos e o próprio mestre principal da agremiação indicam) tratá-lo como mestre auxiliar ou mestre suplente, pois, comumente é visto a tomar o protagonismo.

Revela que o período junto ao mestre tem lhe garantido muito aprendizado e que o perfil humilde e motivador deste para com ele o inspira a seguir no meio do maracatu. Sonha que, uma vez tendo o mestre se afastado, possa assumir em definitivo o posto de mestre dessa agremiação. Ainda no maracatu, mas atuando de modo autônomo, ele é Catita, figura que sai na agremiação coletando dinheiro e animando o público com sua irreverência e comportamento anárquico e libidinoso, fazendo uma caricatura de uma mulher de padrões refutáveis.

10 Personagem de inspiração mítico-simbólica no Maracatu de Baque Solto evidencia, com destaque, em sua indumentária, evoluções e rituais, a origem afro-indígena do "brincante". Permeado de crenças, supertições e rituais populares, Tuxáua ou Caboclo de Pena, como também pode ser conhecido, é comumente chamado de Arreamá, segundo muitos participantes por ter o poder de "arriar" o mal. 
É comum que as Catitas saiam sozinhas durante o carnaval, não necessariamente acompanhadas de um maracatu. Então, na manhã de domingo, Bernardo Soares sai pelas ruas da cidade com sua personagem "fogosa" que ele denominou de "Catita Thainá". Essa é outra fonte de recursos. Informa que já chegou a receber $\mathrm{R} \$ 200,00$ e oferece os rendimentos como ajuda para o maracatu, mas que, no último ano, além dos rendimentos não passarem de $\mathrm{R} \$ 80,00$ preferiu ficar para si já que estava desempregado e sem recursos financeiros.

Para além do Maracatu de Baque Solto, mas ainda no campo da cultura popular local, ele é um grande admirador do Cavalo Marinho, tendo não só forte apetência, mas competências cênicas e coreográficas na participação dessa manifestação cultural. Atua principalmente em figuras como Mateus, Bastião e, principalmente, Mestre Ambrósio, personagem de destaque nos referidos grupos, por sua máscara rudimentar. Indica muito gosto por ciranda e coco de roda, mas não tem desenvolvido um trabalho mais consistente nesses grupos. Participa mais de modo "recreativo" e por lá encontra muitos amigos que participam de modalidades culturais comuns, devido ao trânsito frequente entre essas agremiações.

Modalidade de cultura popular vinculada aos festejos dedicados ao São João, as quadrilhas juninas são um dos exemplos de expressões da cultura e dos estilos de vida do Nordeste brasileiro que configuram a diversidade cultural da região estudada. Geralmente se apresetam em forma de dança e coreografias cênicas, evidenciando tipos sociais e figuras características do contexto regional. Com o passar do tempo, os grupos têm se expandido e aglutinando à tradição o aspecto de competição e estetização.

Os hibridismos culturais e as dinâmicas plásticas dos grupos culturais têm multiplicado o número de agremiações pelas periferias da Região Metropolitana do Recife pelas áreas mais urbanizadas de cidades do interior do estado de Pernambuco. configuração não diferente se constata em outras cidades da região Nordeste. Nesse processo plural de construção de novas agremiações que surgem no criativo contexto de mediação cultural concorrencial, os jovens de periferia estão cada vez mais atraídos pelos grupos. Participar de uma quadrilha é encontrar um espaço de desenvolvimento e exibição do talento artístico, seja na música, nas artes plásticas, na dança ou nas interpretações cênicas e circenses.

Bernardo Soares iniciou sua participação em quadrilhas juninas como dançarino. Aos poucos, foi avançando posições dentro do grupo conforme a evolução de seu talento era reconhecido no seio da equipe. Depois passou a representar a figura de Lampião e de Rei, apresentando seu conhecimento e competência cênica. Contudo, o papel mais importante que o presente "ator plural" interpreta nessa modalidade cultural é o de marcador, figura de liderança grupal e interação com o público espectador. Ainda no âmbito das interpretações cênicas, atuou na direção e elenco de espetáculos populares da Paixão de Cristo, representando os papéis de um dos ladrões e, em outra cena, de apóstolo de Cristo.

Bernardo Soares tem um perfil de engajamento cultural, participa de uma associação filantrópica local de manutenção de tradições culturais e de elaboração de projetos comunitários. 
Suas participações nessas atividades, especialmente na preparação temática das quadrilhas juninas, consistem em realizar pesquisas e em se tornar conhecedor do assunto abordado pelo tema do grupo, demonstrando desenvoltura e adquirindo saberes e experiências. Outro fator de socialização relevante foram as apresentações culturais que realizou fora do país. Como componente de grupo de cultura local e convidado por artistas da região, ele viajou por países como Portugal, França e Senegal. Conta a experiência com boas recordações.

\footnotetext{
Cheguei em casa e disse: "Mãe, vou para França". "Pra França, fazer o quê na França, menino?" "Vou tocar, mãe". Ela falou: "Tá certo, mas vai ganhar dinheiro?" "Vou, num vou o quê? A senhora vai ver eu chegar aqui com o mói!" [...] "Aprendi novas linguagens, as culturas... Gratificante demais, o cara conhecer..."
}

Viajar por terras estrangeiras lhe garantiu novas vivências e aprendizados na área cultural e tocou sua sensibilidade social, quando conta que se deparou com as condições sociais paupérrimas de vida dos indivíduos em Senegal: "Lá eu vi a realidade do ser humano, a galera comendo 'biscoito de barro'. Todo mundo deu uma coisa para ajudar. Eu doei uma bermuda e uma camisa".

Para além da cultura popular, mas não fora de contextos comunicativos com o quadro interacional local, gosta de consumir cultura global, adora filmes antigos de ação, principalmente os de Bruce Lee, e de comédia, principalmente os dos Trapalhões. Assiste a novelas diariamente, tendo como sua preferida América, exibida pela Rede Globo em 2005. Aponta que o gosto por essa foi pelo fato de acompanhar as disputas de rodeios que faziam parte da trama.

Revela que entre as modalidades esportivas tem mais gosto pelo consumo que pela prática competitiva, considera a dança relacionada ao esporte, mas lamenta a falta de apoio que existe na região. Algumas vezes, de modo recreativo, joga futsal e voleibol, este último na praça da cidade, e diz não ligar para os comentários pejorativos de que é um esporte feminino e os preconceitos de participar com muitos amigos gays. Assiste com frequência a combates de UFC - Ultimate Fighting Championship - e se diz fã dos lutadores Anderson Silva e José Aldo. Assiste aos jogos de futebol do campeonato brasileiro, sendo torcedor do Corinthians e acompanha diariamente programas de rádio e de TV sobre futebol, sendo seu preferido o Jogo Aberto, exibido nas tardes de domingo pela Rede Bandeirantes.

Suas apetências por futebol podem ser visualizadas na relação estreita com o avô falecido que presidia um clube esportivo municipal. Tais apetências foram reforçadas pela relação com o professor de educação física que lhe ensinou fundamentos do esporte e pelo massivo poder de alcance que tal modalidade exerce, influenciando-o, inclusive, a ter predileção por times futebolísticos da região Sudeste do Brasil. Do ponto de vista local, tem certo apreço pelo Sport Clube do Recife "por homenagem" a um tio já falecido, mas não se considera um torcedor do time pernambucano.

$\mathrm{Na}$ música, ele gosta muito de músicos da MPB, em especial artistas como Caetano Veloso, Maria Gadú, Ana Carolina, Alceu Valença, e de músicos instrumentistas regionais. 
Não gosta de Rock, mas aprecia artistas locais que mesclam estilos de música estrangeira com aspectos da cultura local, e cita artistas como Siba, Maciel Salú, Isaar, Ticuqueiros e outros, tendo ele contato e projetos com alguns desses. Gosta de músicas diversas da cultura popular, como as de produção local de sua região, mas também gosta de artistas pop como Michael Jackson e Chris Brown. Revela admiração pelas danças dos artistas pop stars. Gosta e ouve com frequência música Reggae, especialmente por meio de grupos como Mato Seco e Ponto de Equilíbrio. Gosta muito de música brega, sobretudo no cenário da música brega romântica pernambucana. São canções que lhe tocam sentimentalmente e inspiram como artista. Segundo ele, para compor músicas de maracatu. Sobre o assunto, comenta:

Uma cantora de brega estimula a fazer marcha de maracatu. Não gosto de brega podre, aquele vai novinha desce tal, gosto de brega com letra, eu gosto muito, viajo nessas letras.

Revela inclusive que no show de Musa do Calypso, na ocasião do encerramento dos festejos juninos, emocionou-se muito com as músicas acabou por passar do limite em relação ao consumo de bebida alcoólica, tendo sido socorrido com elevado nível de embriaguez.

Seu consumo cultural se reflete em estilos de vida, sobretudo de cultura urbana. Gosta de roupas de marca, mas a camisa preferida ainda é a multicolorida, característica do mestre de maracatu, assim como o chapéu, indispensável. Em suas práticas, ele demonstra grande variedade cultural interindividual, tanto pelo consumo quanto pela re/produção cultural. Destaco as disposições culturais "outsiders" de Bernardo Soares que gosta e participa de competições de dança nas modalidades freestyle, passinho e Hip Hop, tendo sido posicionado em $4^{\circ}$ lugar nas batalhas de Beat Box, na edição local da Red Bull BC One.

Durante a última entrevista, ele me relatou o projeto de criar uma banda de música alternativa inspirada na banda Cordel do Fogo Encantado. A ideia seria reunir cultura popular, poesia e musicalidade regional, harmonizando instrumentos locais, os mesmos utilizados pelos maracatus e outros grupos locais, a exemplo de bandas como Mestre Ambrósio, Siba e a Fuloresta, Ticuqueiros e artistas como Maciel Salú, com instrumentos eletrônicos. Para esse projeto, já estava reunindo componentes, adquirindo recursos e negociando estratégias com um produtor local. Mas também estava encontrando dificuldades de ordem financeira que prejudicavam o andamento desejável das atividades.

Percebe-se a variação cultural interindividual quando se observa a posição de Bernardo Soares em relação a muitos de seus "pares" de maracatu, como também, e principalmente, intraindividual, constatando as variações internas dinamizadas no interior de um mesmo ator. Quando ampliamos o zoom e adotamos uma perspectiva de análise microssociológica e individual, é possível perceber, por dentre as dobras do social, a pluralidade disposicional e a multiplicidade de práticas. 
Tais variações e práticas plurais são também observadas em seu percurso social e ações religiosas. Ele é católico, religião que teve contato na socialização intrafamiliar. Com o interesse gradual que vai tendo a partir da infância por cultura popular, vai expandindo seu olhar de modo a alcançar a cultura religiosa dos grupos populares. Ainda na adolescência, quando participava de caboclinho, teve conhecimento das práticas religiosas ${ }^{11}$ que eram executadas pelo grupo de que fazia parte, embora, naquele momento, não tivesse participação direta.

Já no maracatu e tendo maior experiência, passa a acompanhar tais trabalhos, especialmente os preparos ligados a sua figura representativa que era o arreamá. Essa fase foi de descobertas da crença e interiorizações motivacionais postas em prática tempos depois. No momento em que passa a interessar-se pelo toque de instrumentos do maracatu, ele vai fazer parte do terno exercendo funções musicais percussivas, por esse caminho vê ativado seu interesse em fazer parte de maneira mais assídua sua filiação à umbanda, tornando-se tocador de um terreiro de sua cidade durante celebrações religiosas. Ressalta ainda que seu interesse era também financeiro, pois recebia pelo serviço, mas a convivência naquele espaço reaguçou e consolidou seu maior interesse, o gosto e a crença pelas religiões de matriz africana e indígena. Ao todo, foram mais de dois anos tocando no terreiro de umbanda de sua cidade. Foi a primeira vez escondido da mãe. Sobre o primeiro contato com o terreiro, ele conta:

Comecei a tocar, quando ele (o Pai de Santo) baixou espírito. Eu fiquei com medo, vei, medo da porra, medo, medo, medo mermo. Aí os povo chegaram e dizia fique com medo não tal". Nesse dia ganhei dinheiro e cheguei em casa e disse: "Oia, mãe, ganhei dinheiro". Ela disse: "Ganhasse dinheiro onde?" Eu falei: "Toquei macumba ali pro menino ali”. Ela se assustou.

Quando perguntado mais detalhadamente sobre suas apetências e crenças/práticas religiosas afro-brasileiras, ele responde:

Eu gosto muito, tem uns espíritos que gosto de ver na roda de Xangô como a "Pomba-gira" porque ela baila no salão e ela fala como se fosse uma pessoa da família, que conhece você" [...] Eu me identifico muito com Oxum. [...] "Sempre que tem festa eu vou, levo cigarro, bebida, eu sempre agrado" Quando vou e não toco, o mestre chega pra mim e diz: "Você vir para minha festa e não tocar? Isso é um filho desnaturado" Aí eu tenho que ir tocar.

Questiona os preconceitos sofridos pelos umbandistas que afirmam de modo racista, intolerante, homofóbico e sexista que "Quem vai para macumba ou é frango ou é puta ou é sapatão e não é assim!".

11 Informações mais detalhadas e etnográficas sobre a cultura religiosa do Maracatu de Baque Solto, suas crenças, rituais e práticas, ver: SENA, José Roberto Feitosa de. Notas Etnográficas sobre Religiosidades populares circulares no Maracatu de Baque Solto Cruzeiro do Forte, Recife/PE. Áltera - Revista de Antropologia, João Pessoa, v. 2, n. 3, p. 37-51, jul. / dez. 2016. 
Revela que no começo sua mãe reclamava muito, mas depois não mais. Já seu irmão sim, pois é evangélico da Assembleia de Deus e discorda das práticas religiosas afro-brasileiras. Seu irmão mais velho o influenciou muito para participar do maracatu, era músico. Ainda criança, Bernardo Soares convivia com seu irmão, e os laços estreitos entre eles foram fatores relevantes para sua participação e adesão ao maracatu, iniciando esse caminho pelo caboclinho. Os mesmos laços afetivos que o interligam a seu irmão e produzem efeitos influenciadores sobre ele são também responsáveis, entre outros fatores, pelo sentimento de ambivalência que possui hoje pelas crenças afro-religiosas. Esse sentimento também se dá de maneira inversa, uma vez que seu irmão frequentemente se interessa por assuntos de maracatu e dialoga com ele, mas não mais participa diretamente por questões de conduta religiosa. Conta que, a convite do irmão, tem participado de alguns cultos e, a cada participação, tem se sentido mais afetado pelo discurso que chega até ele, desde o do seu irmão até os proferidos pelo pastor, como num caso de um discurso específico direcionado a ele:

Uma vez fui na igreja e um pastor disse: "Tu tá pensando que essa tua vidinha de tocar e dançar é por muito tempo é? Tu vai tocar e dançar é pra Deus, tu vai salvar muitas almas, tu vai ser o mediador da igreja". Na verdade e não sei nem como é mas ele falou e eu sinto que é forte. Deus tá presente ali.

Nessa relação de forças que tem como pano de fundo a relação intrafamiliar interirmãos existe uma equação que tem dados qualitativos constatados nos desdobramentos da segunda e terceira entrevista, pendido para a iminência de uma conversão de Bernardo Soares, iniciada por um caminho constante que vai dos sucessivos e insistentes convites do irmão em participar de cultos evangélicos e passa pelo gradativo afastamento dos cultos afro-brasileiros. Na interseção entre a socialização localizada intrafamiliar (mediada pela interação face a face com seu ente afetivo) e a socialização em macroescala, pela construção/propagação, de maneira globalizada, do discurso de refutação às culturas/religiões de matrizes afro-híbridas, gesta o coeficiente que cria sentidos ambivalentes no retratado, estando ele entre estados de pureza e perigo:

Eu vejo que... Tipo... Eu creio que Jesus tá voltando, velho, tem muita coisa que tá acontecendo no mundo aí que... Eu penso, penso muito em seguir a lei. Acho que o maracatu não é pecado, é uma profissão, desde que não siga a lei do candomblé, você sendo evangélico e tendo o maracatu como profissão não vejo pecado, o errado é você ir pra dentro de candomblé, errado eu vejo isso aí, tá ligado? Fora isso, tá de boa!

Na última entrevista Bernardo Soares tinha um desejo aparentemente paradoxal, de que sua conversão estava próxima e ao mesmo tempo não iria abandonar suas atividades na cultura popular, mas vivia um grande dilema, pois a igreja a que frequentava na condição de visitante não aceitava tal combinação. Ele vivia momentos de crise, mas não queria se afastar do maracatu e de outras manifestações de cultura popular que marcam sua trajetória, pelo contrário, fazia 
planos e galgava mais espaços de atuação e reconhecimento. No momento, estava administrando esse contexto como um bricoleur de circularidades que compõe sua religiosidade e estilo de vida. De modo não institucional, ele incorporou de maneira seletiva práticas e visões de um e de outro mundo social, fabricando sua visão/prática religiosa.

Quando perguntado se haveria um momento em que teria de tomar uma decisão e optar entre sua atual vida de agente na cultura popular ou de adepto (e também agente) de religião evangélica, ele revelou pensar que isso acontecerá e achar que não vai demorar, mas não sabe quando e não faz planos racionais para isso. No momento, o que tem buscado é conseguir um emprego e galgar novos espaços culturais. Para isso, não poupa pedidos de interseções à (s) sua (s) divindade (s) do híbrido panteão afro-brasileiro.

\section{Considerações finais}

A observação plural das plurais ações dos atores permite não negligenciar as micromobilidades e microvariações, trazendo para a observação relevantes aspectos do ator de modo a não limitá-lo e estigmatizá-lo. Isto é, o ator do maracatu é visto dentro e fora dele, para além dele. Assim, é possível compreender as próprias variações, hibridismos e circularidades culturais do grupo, tendo em vista que os repertórios de disposições são adquiridos, re/ elaborados e efetivados extra e intrarrelação grupal.

Tais resultados nos permitiram constatar ainda que as práticas e os comportamentos variam de acordo com a trajetória (diacronia) e a contexto da ação (sincronia). Observei, através dos multimétodos aplicados (entrevista em profundidade, observação direta e participante, fotoetnografia, entre outros), que as crenças e práticas culturais dos atores no maracatu não eram compartilhadas por todos, tendo ainda casos de maior ou menor competência e maior ou menor apetência para participação.

Bernardo Soares foi um retratado que se mostrou com grande variação cultural, mobilidade entre espaços e estilos de vida, com maior predisposição para misturas de gênero e com um perfil do tipo pendular, ora consonante para o grupo cultural ora dissonante, agindo de acordo com o contexto da ação. Bernardo Soares mostra competência e apetência para as culturas populares de sua região sem se desvencilhar do cenário pop tanto da cultura local, que em parte se inspira nas culturas populares, quanto na cultura de massa. No que tange às suas influências, tem como forte gênese de disposições motivadoras a influência do irmão mais velho, que no passado o influenciou a participar e criar gosto pelo maracatu e que no presente, convertido à igreja evangélica, exerce de maneira não direta uma influência para a conversão religiosa. Tal contexto que o acompanha constantemente causa o dilema de continuar ou não na religião afro-brasileira, especialmente nos cultos de umbanda e jurema, frequentemente estigmatizados nos discursos pentencostais. Vive atualmente na bifurcação entre continuar no maracatu ou converter-se, "aceitar a palavra" e enfrenta esse desafio pessoal procurando 
conciliar as perspectivas de vida ambivalentes sem, contudo, efetivar o incipiente processo de conversão.

A pesquisa se baseou em casos empíricos publicados na sociologia portuguesa a fim de encontrar terreno sólido para um programa científico emergente e com dispositivo sociológico inédito, sendo nesta perspectiva adaptado e atualizado para a especificidade e os interesses de cada pesquisa. Adotei tal perspectiva sem ainda assim me limitar a ela, buscando a complementariedade com outras técnicas e recursos.

Sendo assim, considero que a aplicação deste aporte teórico e metodológico permitiu conhecer mais a fundo esses indivíduos, reconhecendo quem são e como vivem, por que mundos sociais transitam e como constituem e agem no mundo social do Maracatu de Baque Solto. Considero ainda que investigar tal tema à luz desse programa científico pode e dever ser suscetível de críticas, mas que é antes um fator desafiador, pois tentou analisar a cultura popular, tão pesquisada e debatida entre as ciências sociais por um viés inovador e ainda embrionário, desafiando as barreiras metodológicas e refutando os fazeres praxes da sociologia.

\section{Referências}

AMÂNDIO, Sofia Lai. O fio constitutivo da sociologia empírica de Bernard Lahire. Sociologia, Problemas e Práticas, Lisboa, n. 76, p. 33-49, 2014.

BORGES, Sheila. O repórter-amador: uma análise das disposições sociais motivadoras das práticas jornalísticas do cidadão comum. 2013. Tese (Doutorado em Sociologia) - Programa de Pós-Graduação em Sociologia, Universidade Federal de Pernambuco, Recife.

GOMES, Rui Machado. (coord.). Fuga de cérebros: retratos da emigração portuguesa qualificada. Lisboa: Bertrand, 2015.

JOUCOSKI, Emerson. Desenvolvimento profissional e inovação curricular na Licenciatura em Ciências da UFPR Litoral. 2015. Tese (Doutorado em Ciências) - Programa de Pós-Graduação Interunidades em Ensino de Ciências, Universidade de São Paulo, São Paulo.

LAHIRE, Bernard. A cultura dos indivíduos. Porto Alegre: Artmed, 2006.

LAHIRE, Bernard. O homem plural: as molas da ação. Lisboa: Instituto Piaget, 2001.

LAHIRE, Bernard. Retratos sociológicos: disposições e variações individuais. Porto Alegre: Artmed, 2004.

LOPES, João Teixeira; AMÂNDIO, Sofia; ABRANTES, Pedro. (coords.). A vida entre nós: Sociologia em carne viva. Porto: Deriva, 2016.

LOPES, João Teixeira; AMÂNDIO, Sofia; ABRANTES, Pedro. (coords.). Registos do actor plural: Bernard Lahire na Sociologia Portuguesa. Porto: Afrontamento, 2012.

MASSI, L. Relação aluno-instituição: o caso da licenciatura do Instituto de Química da UNESP/Araraquara. 2013. Tese (Doutorado em Ensino de Ciências) - Faculdade de Educação, Universidade de São Paulo, São Paulo.

PONTES, Thiago Panica. “Crescer na vida”: trajetórias de micromobilidade nos meios populares. 2015. Tese (Doutorado em Sociologia) - Institutos de Estudos Sociais e Políticos, Universidade do Estado do Rio de Janeiro, Rio de Janeiro. SENA, José Roberto Feitosa de. Maracatus Rurais do Recife: entre a religiosidade popular e o espetáculo. 2012. Dissertação (Mestrado em Ciências das Religiões) - Programa de Pós-Graduação em Ciências das Religiões, Universidade Federal da Paraíba, João Pessoa. 
REIS, Juliana Batista dos. Transversalidade nos modos de socialização e individuação: experiências juvenis em rede. 2014. Tese (Doutorado em Educação) - Faculdade de Educação, Universidade Federal de Minas Gerais, Belo Horizonte.

SÁ, Márcio; ROCHA, Emerson. O Batalhador feirante e sua administração. In: SOUZA, Jessé. Batalhadores brasileiros: nova classe média ou nova classe trabalhadora? Belo Horizonte: UFMG, 2012. P. 85-104.

SOUZA, Jessé. A ralé brasileira: quem é e como vive. Belo Horizonte: Ed. Da UFMG, 2009.

Recebido em: 10/12/2018

Aceito em: 20/12/2018 